Article

\title{
Fusion of Heart Rate, Respiration and Motion Measurements from a Wearable Sensor System to Enhance Energy Expenditure Estimation
}

\author{
Ke Lu ${ }^{1, *}$, Liyun Yang ${ }^{1,2} \oplus$, Fernando Seoane ${ }^{3,4,5}$, Farhad Abtahi ${ }^{1,2} \oplus$, Mikael Forsman ${ }^{1,2}$ \\ and Kaj Lindecrantz ${ }^{2,4}$ \\ 1 School of Engineering Sciences in Chemistry, Biotechnology and Health, KTH Royal Institute of Technology, \\ Hälsovägen 11C, 14157 Huddinge, Sweden; liyuny@kth.se (L.Y.); farhad.abtahi@ki.se (F.A.); \\ mikael.forsman@ki.se (M.F.) \\ 2 Institute of Environmental Medicine, Karolinska Institutet, Solnavägen 1, 17177 Solna, Sweden; \\ kaj.lindecrantz@ki.se \\ 3 Department of Clinical Science, Intervention and Technology, Karolinska Institutet, \\ Hälsovägen 7, 14157 Huddinge, Sweden; fernando.seoane@ki.se \\ 4 Swedish School of Textiles, University of Borås, Allégatan 1, 50190 Borås, Sweden \\ 5 Department of Biomedical Engineering, Karolinska University Hospital, 1, 17176 Solna, Sweden \\ * Correspondence: kelu@kth.se; Tel.: +46-765-910-501
}

Received: 17 August 2018; Accepted: 11 September 2018; Published: 14 September 2018

\begin{abstract}
This paper presents a new method that integrates heart rate, respiration, and motion information obtained from a wearable sensor system to estimate energy expenditure. The system measures electrocardiography, impedance pneumography, and acceleration from upper and lower limbs. A multilayer perceptron neural network model was developed, evaluated, and compared to two existing methods, with data from 11 subjects (mean age, 27 years, range, 21-65 years) who performed a 3-h protocol including submaximal tests, simulated work tasks, and periods of rest. Oxygen uptake was measured with an indirect calorimeter as a reference, with a time resolution of $15 \mathrm{~s}$. When compared to the reference, the new model showed a lower mean absolute error $\left(\mathrm{MAE}=1.65 \mathrm{~mL} / \mathrm{kg} / \mathrm{min}, \mathrm{R}^{2}=0.92\right)$ than the two existing methods, i.e., the flex-HR method $\left(\mathrm{MAE}=2.83 \mathrm{~mL} / \mathrm{kg} / \mathrm{min}, \mathrm{R}^{2}=0.75\right)$, which uses only heart rate, and arm-leg HR+M method $\left(\mathrm{MAE}=2.12 \mathrm{~mL} / \mathrm{kg} / \mathrm{min}, \mathrm{R}^{2}=0.86\right)$, which uses heart rate and motion information. As indicated, this new model may, in combination with a wearable system, be useful in occupational and general health applications.
\end{abstract}

Keywords: energy expenditure; wearable device; accelerometer; impedance pneumography; neural network

\section{Introduction}

The energy expenditure (EE), as an indicator of metabolic state and physical activity level, provides valuable information that can be used for occupational health and safety design [1], exercise, and daily life management, and prevention and treatment of health problems such as obesity and diabetes [2]. Direct measurement methods of EE or oxygen consumption $\left(\mathrm{VO}_{2}\right)$, a commonly-used indicator of $\mathrm{EE}$, requires expensive and sophisticated equipment, such as the direct calorimetry using metabolic chamber, the double labeled water method, and indirect calorimetry with a face mask, which are not suitable for daily free-living use [3]. Therefore, indirect measurement techniques using wearable sensors are desired, and have attracted significant attention in the last two decades; consequently, considerable effort has been allocated to the issue [4-32]. 
Heart rate (HR) monitoring is often used to estimate EE, as it has a good linearity with oxygen consumption in a large range of aerobic work $[13,21]$. The relationship between HR and EE at an individual level can be established through a calibration procedure, i.e., maximal or submaximal tests performed with a treadmill or cycle ergometer, which requires time and resources [33]. However, the poor relationship between $\mathrm{HR}$ and $\mathrm{EE}$ in resting and low intensity activities is an important limiting factor [24]. The $\mathrm{HR}-\mathrm{VO}_{2}$ relation can vary in different activities [19], e.g., difference has been reported between upper body and lower body activities [34]. In addition, HR is affected by several factors that are not directly related to metabolism e.g., mental stress, emotions, and medication [16].

Accelerometry is also a popular tool to estimate physical activity related EE in free-living conditions. With count-based methods [11,35], the activity count is calculated using acceleration, and then directly linked to EE, while the type of activity being performed is not considered [6]. In activity related methods $[4,7,12]$, firstly, the activity recognition is preformed, then the EE is estimated through a look-up table or by using the activity specified EE model [6]. The acceleration (ACC) measurement directly reflects the movement information. However, it lacks the information about the effort of the movements, which limits its effectiveness for assessing complex activities involving interaction with other objects, such as manual handling. Several methods that utilize HR and ACC have been proposed, which improves the estimation of EE by the sole use of HR or ACC $[9,36]$.

Respiration is another factor that is related to EE [14]. Several studies have demonstrated that pulmonary ventilation $\left(\mathrm{V}_{\mathrm{E}}\right)$ has better linearity with EE compared to the HR $[37,38]$. As an accurate $\mathrm{V}_{\mathrm{E}}$ measurement requires devices with facemasks or mouthpieces, the real application is very limited in free-living conditions. Recent developments in wearable technologies, such as impedance pneumography (IP), inductive plethysmography, and piezoresistive pneumography integrated in smart clothing [39-43], give new opportunities to use portable respiration measurement devices for EE estimation in a free-living setting, and preliminary studies have been carried out $[15,18]$.

The purpose of this study was to develop and test a method that uses a combination of information from measurements of heart rate, respiration, and accelerations to estimate energy expenditure. The measurements were acquired through a wearable sensor system, and integrated by a model based on neural network. The wearable sensor system was developed under our research projects towards automatic risk assessment at work [44,45]. A lab experiment was implemented to support the development of the model and evaluate the developed system and estimation model. The proposed method was compared with two existing methods: HR-flex [28], a HR based method that uses a bi-linear model to improve the estimation in low intensity, and Arm-Leg HR+M [29,36], a method which uses combined HR and ACC measurements, with independent arm and leg calibration. The results showed improved accuracy over the two existing methods. In addition, the proposed method does not require complex lab calibration, which can dramatically improve the usability of such a system in field settings.

\section{Materials and Methods}

\subsection{The Wearable Sensor System}

The wearable sensor system and the sensor placement are shown in Figure 1. The vest, reported in $[40,46]$, includes four textile electrodes made by conductive fabric. One pair of electrodes was used for IP current injection, and the other was used for electric potential sensing for IP and ECG. A compact recorder, ECGZ2 (Z-Health Technologies AB, Borås, Sweden), for ECG and electrical bioimpedance was connected to the vest and placed in a pocket on the shoulder strap of the vest. The frequency of the injection current for impedance measurement was $50 \mathrm{kHz}$. ECG and IP signals were recorded with sampling rates of $250 \mathrm{~Hz}$ and $100 \mathrm{~Hz}$, respectively. Four 3-axis accelerometers (AX3, Axivity Ltd., Newcastle, UK) were placed on both wrists, using rubber wristbands, and on the thighs, using trousers with specially designed pockets to hold the accelerometer units. The acceleration was recorded at $100 \mathrm{~Hz}$. 


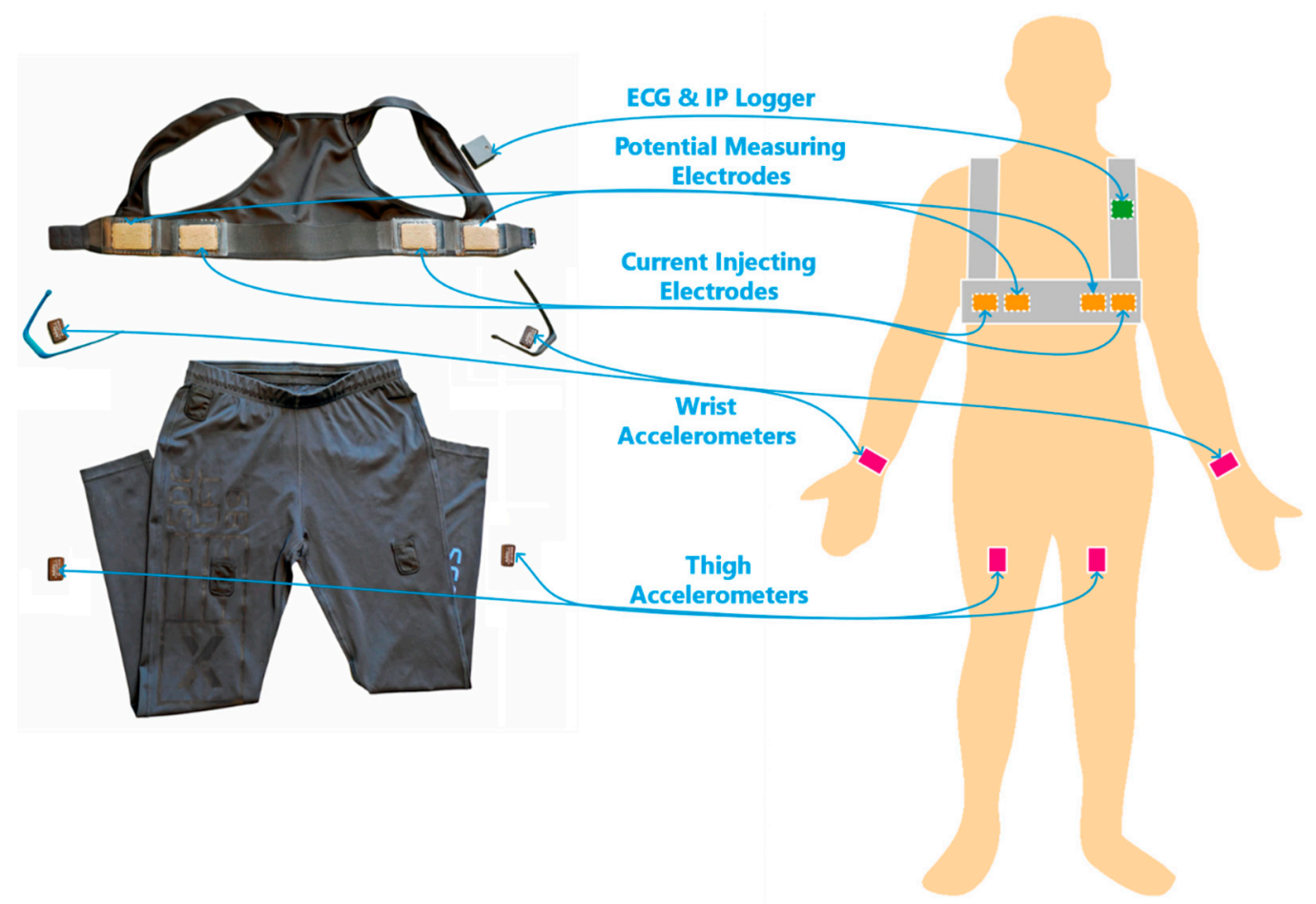

Figure 1. The wearable sensor system and its placement. The system includes a vest with textile electrodes, a wireless ECG and IP recording unit, 4 accelerometers, rubber wristbands, and trousers with specially designed pockets.

\subsection{Data Collection}

\subsubsection{Participants}

Nine men and three women participated in the laboratory experiment implemented in GIH, the Swedish School of Sport and Health Sciences, Stockholm, Sweden. The subjects consisted of a homogeneous group with young male subjects, and a heterogeneous group with both male and female participants in different age groups. Data from one subject was removed from the analysis because of the lack of a vest with a suitable size for the participant, which resulted in poor ECG and IP signal quality. The detailed characteristics of the included participants are shown in Table 1. All participants provided written informed consent. Ethical approval for the study was obtained from the Regional Ethical Review Board in Stockholm (Dnr 2016/724-31/5).

Table 1. Characteristics of included participants (median [range]).

\begin{tabular}{cccc}
\hline & Men $(N=9)$ & Women $(N=2)$ & All $(N=11)$ \\
\hline Age $($ year$)$ & $27[21-65]$ & $43[25-61]$ & $27[21-65]$ \\
Height $(\mathrm{cm})$ & $181[171-199]$ & $169[165-173]$ & $177[165-199]$ \\
Weight $(\mathrm{kg})$ & $77[51-89]$ & $60[58-62]$ & $75[51-89]$ \\
$\mathrm{BMI}\left(\mathrm{kg} / \mathrm{m}^{2}\right)$ & $22.8[17.4-25.6]$ & $20.9[20.7-21.2]$ & $22.6[17.4-25.6]$ \\
$\mathrm{VO}_{2} \max (\mathrm{mL} / \mathrm{min} / \mathrm{kg})$ & $42.9[32.1-54.6]$ & $35.6[30.9-40.3]$ & $40.3[30.9-54.6]$ \\
\hline
\end{tabular}

\subsubsection{Experiment Protocol}

The participants were asked to avoid intense physical activity for 1 day before the experiment, and to refrain from eating, smoking, drinking tea, coffee, or alcohol for at least $2 \mathrm{~h}$ beforehand. The experiment process took about $3 \mathrm{~h}$. During the experiment, $\mathrm{VO}_{2}$ was measured by a computerized metabolic system (Jaeger Oxycon Pro, VIASYS Healthcare GmbH, Würzburg, Germany), where a facemask was worn by the participants. The experiment protocol 
consisted of three categories of activities: resting, simulated working tasks, and submaximal tests. The list of performed tasks and corresponding $\mathrm{VO}_{2}$ levels measured in the experiment is presented in Table 4 under the result section. After each task, the subject had a break for 5 to 25 min, until the HR returned to within 10 percent of the resting HR.

The resting test included resting in three postures: $20 \mathrm{~min}$ in lying, $5 \mathrm{~min}$ in sitting and $5 \mathrm{~min}$ in standing. During the resting test, the resting energy expenditure (REE) was measured. Five different working tasks, with different intensity levels and active muscle groups, were performed afterwards. Each of the tasks lasted 8-10 min. The office work required the participant to type on a computer while sitting beside a table. The painting work required the participant to simulate painting a wall at their own pace using a painting pole. The postal delivery work was performed by cycling at a cycle ergometer with $0.75 \mathrm{~kg}$ resistance. The meat cutting work was simulated by pulling a resistance band repetitively. The construction work included arm and whole body lifting tasks. The submaximal tests session consisted of 3 tests. The first was the Chester step test [47], with maximal 5 levels of incremental stepping pace. The second was a walking pace treadmill test as described in [36]. Each level of the treadmill test lasted three minutes. The speed was increased after the first level. From the second level, the inclination was raised by $2 \%$ between each stage. The third test was an arm ergometer test with a constant cadence while the resistance increased between each level [36]. All the submaximal tests were terminated when the HR of the subject reached the $80 \%$ of the age-predicted maximal HR (220 - age).

\subsection{The Model for $\mathrm{VO}_{2}$ Estimation}

The process of the estimation is shown in Figure 2. A multilayer perceptron neural network (MLPNN) with four input units, five hidden units, and one output unit was used to construct the model. The activation function of the hidden layer was hyperbolic tangent sigmoid function, and linear function for the output layer. All features and the output are listed in Table 2. All data were analyzed with 15-s non-overlapping windows. Four features were used that represent $\mathrm{HR}, \mathrm{V}_{\mathrm{E}}$, arm motion and leg motion, respectively. $\mathrm{HR}, \mathrm{V}_{\mathrm{E}}$, and $\mathrm{VO}_{2}$ were normalized by corresponding individual characteristics before being used as the inputs and output of the MLPNN to train a network with good genericization that learns characteristics at the group level.

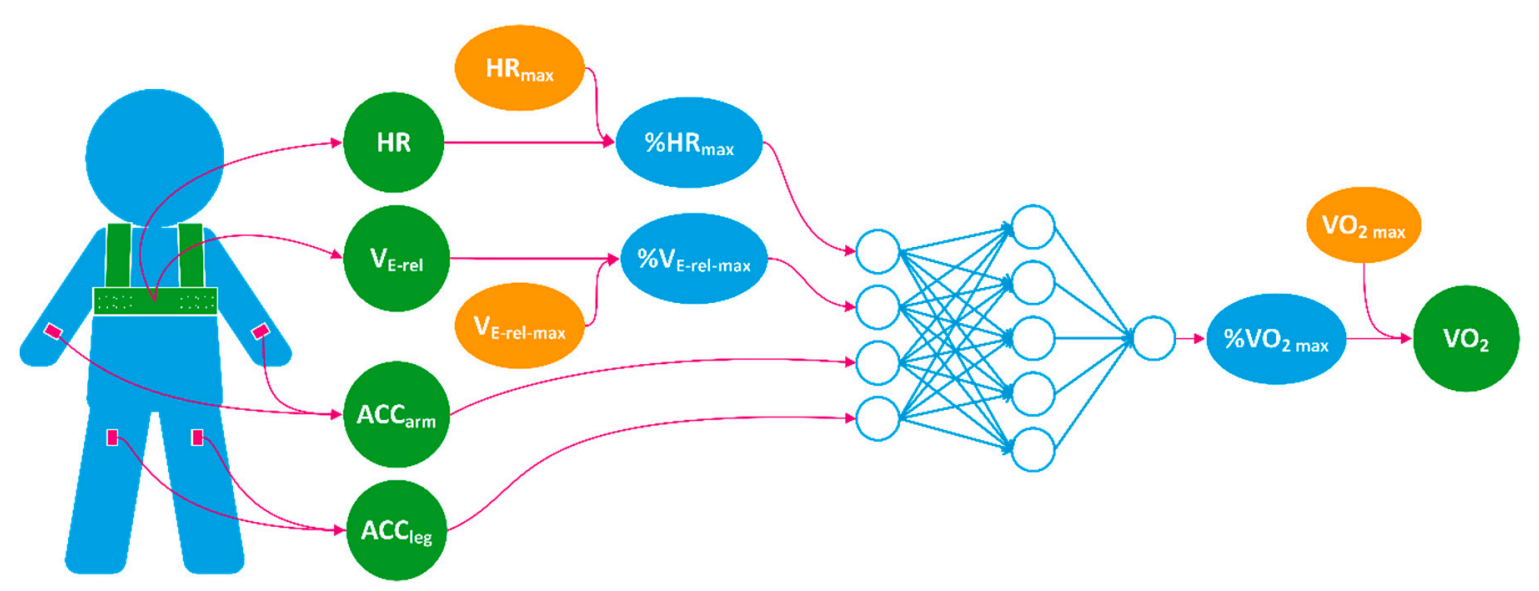

Figure 2. A demonstration of the flow of the oxygen consumption $\left(\mathrm{VO}_{2}\right)$ process. The input and output are explained in Table 2. 
Table 2. Summary of the input features and the output of the neural network.

\begin{tabular}{ccc}
\hline & $\% \mathrm{HR}_{\max }$ & $\mathrm{HR}$ normalized by age predicted $\mathrm{HR}_{\max }$ \\
Input Features & $\% \mathrm{~V}_{\mathrm{E}-\mathrm{rel} \mathrm{max}}$ & $\mathrm{V}_{\mathrm{E}-\text { rel }}$ normalized by estimated $\mathrm{V}_{\mathrm{E}-\text { rel max }}$ \\
& $\mathrm{ACC}_{\mathrm{arm}}$ & Mean absolute value of wrist acceleration \\
& $\mathrm{ACC}_{\text {leg }}$ & Mean absolute value of thigh acceleration \\
\hline Output & $\% \mathrm{VO}_{2 \max }$ & $\mathrm{VO}_{2}$ normalized by estimated $\mathrm{VO}_{2 \text { max }}$ \\
\hline
\end{tabular}

The $\mathrm{VO}_{2}$ measurements were normalized by the individual maximal oxygen uptake $\left(\mathrm{VO}_{2}\right.$ max $)$, which was estimated through the Chester step test with pre-estimated $\mathrm{VO}_{2}$ level on each stage [47]. The HR was normalized by individual maximal $\mathrm{HR}\left(\mathrm{HR}_{\max }\right)$, calculated by $\mathrm{HR}_{\max }=220-$ age. The relative tidal volume $\left(\mathrm{V}_{\mathrm{T} \text {-rel }}\right)$ of each breath was represented by the impedance difference in peak and valley pairs of the filtered IP signal. The relative ventilation $\left(\mathrm{V}_{\mathrm{E}-\mathrm{rel}}\right)$ during each 15-s epoch was acquired by the sum of the $\mathrm{V}_{\mathrm{T} \text {-rel }}$ values in the window. A quadratic relationship between $\mathrm{HR}$ and $\mathrm{V}_{\mathrm{E}-\mathrm{rel}}$ was established for each subject by the least square method using measured HR and $\mathrm{V}_{\mathrm{E}-\mathrm{rel}}$ during the experiment. The maximal relative ventilation $\left(\mathrm{V}_{\mathrm{E}-\mathrm{rel} \mathrm{max}}\right)$ was then estimated by applying the $\mathrm{HR}_{\max }$ to the HR- $\mathrm{V}_{\mathrm{E} \text {-rel }}$ relationship. $\mathrm{V}_{\mathrm{E} \text {-rel }}$ was then normalized by the $\mathrm{V}_{\mathrm{E} \text {-rel max }}$ and fed to the network. The acceleration data was first band pass filtered with a $0.25-6 \mathrm{~Hz}$ passband; then, the mean absolute acceleration was computed for each 15-s epoch. For the arm and leg acceleration, the higher value from the right and the left sides of each epoch was picked.

\subsection{Model Training and Cross Validation}

The so-called Leave one subject out (LOSO) validation method was used. In repeated trials, all data except one subject was used for training the model; the data of that subject was used for testing the model. The LOSO method avoids test results that are overfitted to individual characteristics. The overall performance of the network was evaluated by combining test results from all LOSO cross validation. The training data was split for training and validation set with a ratio of $6: 4$, and the Levenberg-Marquardt backpropagation was used for the training process.

\subsection{Comparision to Published Methods}

Results from our method were compared with two published methods, i.e., HR-flex [28], one of the mostly used HR based method in the field, and Arm-Leg HR+M method [29,36], a method showed improved accuracy during occupational tasks in our previous evaluation [48]. The inputs and calibration requirements of all methods are listed in Table 3.

Table 3. A comparison of requirements of input data and personalized measurement among the three methods.

\begin{tabular}{ccc}
\hline Methods & Input Data & Additional Individualized Measurements \\
\hline Flex-HR & $\mathrm{HR}$ & Flex HR Point \\
& $\mathrm{REE}$ \\
& $\mathrm{HR}-\mathrm{VO}_{2}$ Calibration \\
\hline Arm-Leg HR+M & $\mathrm{HR}, \mathrm{ACC}_{\text {leg }}, \mathrm{ACC}_{\mathrm{arm}}$ & $\mathrm{REE}$ \\
& $\mathrm{HR}, \mathrm{ACC}_{\text {leg }}, \mathrm{ACC}_{\text {arm }}, \mathrm{V}_{\mathrm{E}-\mathrm{rel}}$ & $\begin{array}{c}\mathrm{Leg} \mathrm{HR}-\mathrm{VO}_{2} \text { Calibration } \\
\mathrm{Arm} \mathrm{HR}-\mathrm{VO}_{2} \text { Calibration }\end{array}$ \\
\hline Proposed & $\mathrm{VO}_{2 \text { max }}$ \\
\hline
\end{tabular}

The flex-HR method [28] considers the nonlinearity in HR-EE relation in low intensity. It uses REE when the HR is below the flex point, and a linear HR-EE relationship when the HR is above the flex point. For the comparison, we chose to use step test data with pre-estimated $\mathrm{VO}_{2}$ levels on each stage for calibration, as it required the same level of test equipment as the new method. The REE was 
measured during the resting test. The flex-point was chosen as the average of the highest HR during rest and the lowest HR during walking on treadmill test.

The Arm-Leg HR+M method $[29,36]$ accounts for the difference in HR-EE response between the upper and the lower body. It uses the level of arm and leg ACC and their ratio to determine the arm specified HR-EE equation, the leg specified HR-EE equation, or the REE for EE estimation. We used a treadmill test and arm ergometer test data to establish the arm and leg calibration respectively, together with a simultaneously measured $\mathrm{VO}_{2}$ level. The calibration requires a treadmill, an arm ergometer, and indirect calorimetry. Thresholds for the ACC level and ratio were re-adapted to our measurement data, as a different accelerometer and acceleration signal processing procedure were used in comparison to the original study.

\subsection{Statistics}

Estimated $\mathrm{VO}_{2}$ in 15-s epochs were compared to the criterion measurements. Bias, the mean absolute error (MAE), the root-mean-square-error (RMSE) and the coefficient of determination $\left(\mathrm{R}^{2}\right)$ were calculated to evaluate the performance. Paired $t$-tests were performed to compare the absolute errors between the new method and each of the two published methods. Bland-Altman plots with error histograms were plotted to assess the agreement and the error distribution.

\section{Results}

The mean levels of measured $\mathrm{VO}_{2}$ for performing each task during the experiment are listed in Table 4 .

Table 4. A summary of tasks performed during the experiments and corresponding mean $\mathrm{VO}_{2}$ level $(\mathrm{mL} / \mathrm{min} / \mathrm{kg})$ of the 11 subjects.

\begin{tabular}{ccc}
\hline Group & Task & VO $_{2}$ Level (Mean \pm SD) \\
\hline \multirow{2}{*}{ Resting } & Lying & $3.78 \pm 0.96$ \\
& Sitting & $3.82 \pm 1.16$ \\
& Standing & $4.01 \pm 0.41$ \\
\hline \multirow{3}{*}{ Work Tasks } & Office Work & $4.01 \pm 1.42$ \\
& Painting Work & $8.51 \pm 1.68$ \\
& Postal Delivery Work & $14.04 \pm 2.37$ \\
& Meat Cutting Work & $7.62 \pm 1.89$ \\
& Construction Work & $12.24 \pm 4.56$ \\
\hline \multirow{3}{*}{ Submaximal Tests } & Step Test & $22.23 \pm 7.71$ \\
& Treadmill Test & $22.88 \pm 8.05$ \\
& Arm Ergometer Test & $11.06 \pm 4.98$ \\
\hline
\end{tabular}

The training and testing results $\left(\% \mathrm{VO}_{2 \max }\right)$ on each subject, as well as the averaged results from the LOSO validation, are shown in Table 5. The RMSE and $\mathrm{R}^{2}$ level from training and testing results were very close, which indicates the method has a good generalization among the participants. The averaged group bias was very low $(-0.16 \%)$. However, a relatively lager bias (maximal $2.71 \%$ ) can be found on individual level in few occasions. No strong relationship was found between the estimation errors and the personal characteristics, such as gender, age, and aerobic capacity.

The results of overall performance in $\mathrm{VO}_{2}$ estimation, measured by individual bias (IB), group bias (GB), MAE, RMSE, and $\mathrm{R}^{2}$ of three methods, are shown in Table 6. The proposed method showed a more accurate estimation ( $\mathrm{IB}=0.42 \mathrm{~mL} / \mathrm{kg} / \mathrm{min}, \mathrm{GB}=-0.01 \mathrm{~mL} / \mathrm{kg} / \mathrm{min}, \mathrm{MAE}=1.65 \mathrm{~mL} / \mathrm{kg} / \mathrm{min}$ ) compared to the flex-HR method (IB $=1.11 \mathrm{~mL} / \mathrm{kg} / \mathrm{min}, \mathrm{GB}=0.69 \mathrm{~mL} / \mathrm{kg} / \mathrm{min}, \mathrm{MAE}=2.83 \mathrm{~mL} / \mathrm{kg} / \mathrm{min}$ ), where estimation error, individual bias, and group bias were significantly reduced $(p<0.001)$. The proposed method also showed a significant improvement $(p<0.001)$ in estimation error over the arm-leg HR+M method (MAE = $2.12 \mathrm{~mL} / \mathrm{kg} / \mathrm{min})$. 
Table 5. Results of the cross validation of the relative $\mathrm{VO}_{2}\left(\% \mathrm{VO}_{2} \max \right)$ from the neural network.

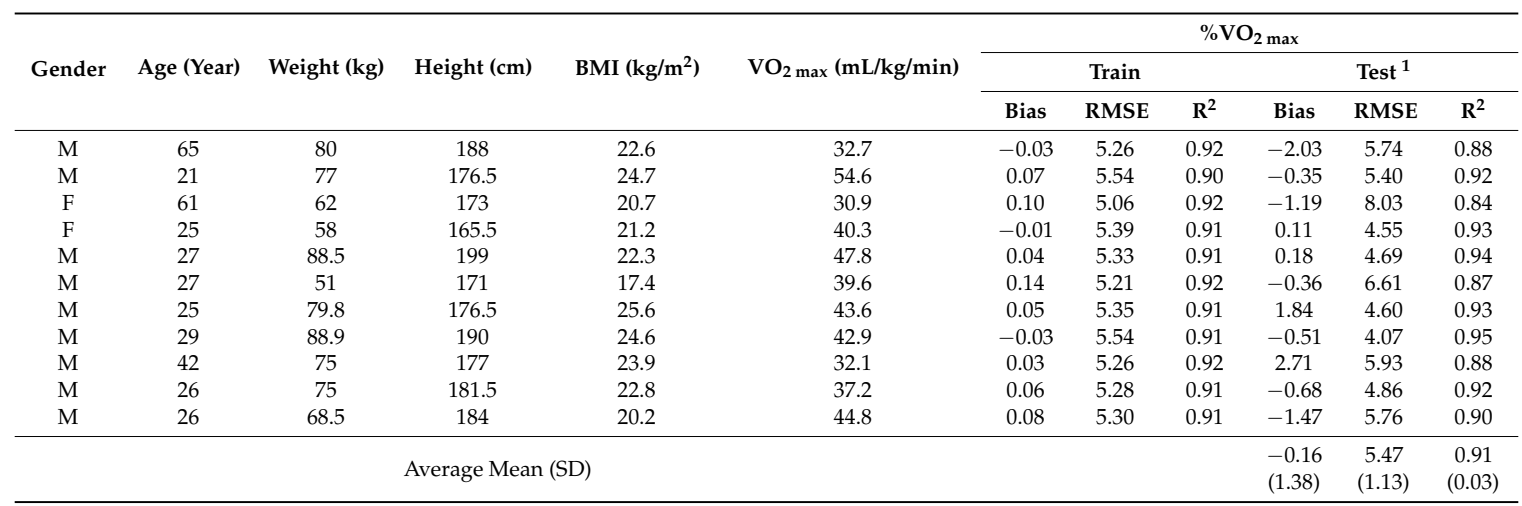

${ }^{1}$ In each row, the data for the specific subject was excluded in the training and used for the testing.

Table 6. Comparison of $\mathrm{VO}_{2}$ estimation results among flex-HR, arm-leg $\mathrm{HR}+\mathrm{M}$, and proposed method $(\mathrm{mL} / \mathrm{kg} / \mathrm{min})$.

\begin{tabular}{cccccc}
\hline Methods & Individual Bias $^{\mathbf{1}}$ & Group Bias & MAE & RMSE & $\mathbf{R}^{\mathbf{2}}$ \\
\hline Flex-HR & 1.11 & 0.69 & 2.83 & 4.00 & 0.75 \\
Arm-Leg & 0.60 & -0.09 & 2.12 & 2.95 & 0.86 \\
HR+M & 0.42 & -0.07 & 1.65 & 2.28 & 0.92 \\
Proposed & 1
\end{tabular}

${ }^{1}$ Mean absolute value of individual biases.

The Bland-Altman plots and the error rate histograms of three methods are shown in Figure 3. The proposed method shows a large improvement in the low intensity region. The mean estimation error rate was also reduced (28.1\%) compared to the other methods ( $44.1 \%$ and $38.4 \%$ respectively).

The errors with each specific activity are shown in Table 7, where for each activity, the worst performance among the three methods is shown in bold and italic. The proposed method has a good overall generalization over different kinds of activities, except that a large bias on the simulated construction work can be found. Comparing to the flex-HR method, the error caused by different HR response to arm and leg activity was reduced in the proposed method by learning from group characteristics without arm calibration, which can be seen from the arm ergometer results, as well as from the top right corner of the Bland-Altman plot in Figure 3.

Table 7. Comparison of task specific errors among three methods ( $\mathrm{mL} / \mathrm{kg} / \mathrm{min})$.

\begin{tabular}{|c|c|c|c|c|c|c|c|c|c|}
\hline & Resting & Office Work & Painting & Postal Delivery & Meat Cutting & Construction Work & Step & Treadmill & Arm Ergometer \\
\hline \multicolumn{10}{|l|}{ Flex-HR } \\
\hline Bias & -0.05 & -0.29 & -0.47 & -2.42 & 1.84 & 1.05 & $-1.05^{1}$ & -0.81 & 4.18 \\
\hline RMSE & 0.90 & 0.84 & 3.89 & 4.15 & 4.33 & 3.90 & $2.85^{1}$ & 2.92 & 5.91 \\
\hline \multicolumn{10}{|c|}{ Arm-Leg HR+M } \\
\hline Bias & -1.42 & -0.93 & -1.90 & -1.59 & -0.16 & -1.09 & -0.38 & $-0.01^{2}$ & $0.00^{2}$ \\
\hline RMSE & 2.50 & 2.09 & 2.55 & 2.57 & 1.56 & 4.44 & 2.53 & $1.82^{2}$ & $1.14^{2}$ \\
\hline \multicolumn{10}{|c|}{ Proposed } \\
\hline Bias & 0.02 & 0.17 & -0.47 & -0.46 & 0.55 & -2.01 & $-1.08^{3}$ & 0.44 & 0.06 \\
\hline RMSE & 0.93 & 0.86 & 1.69 & 2.36 & 1.62 & 3.88 & $2.83^{3}$ & 2.71 & 1.69 \\
\hline
\end{tabular}

The bold and italic numbers indicate the largest error in each activity. ${ }^{1}$ Data used for individual calibration, with pre-estimated $\mathrm{VO}_{2}$ level. ${ }^{2}$ Data used for individual calibration, with measured $\mathrm{VO}_{2}$ level. ${ }^{3}$ Data used for $\mathrm{VO}_{2 \max }$ estimation, with pre-estimated $\mathrm{VO}_{2}$ level. 

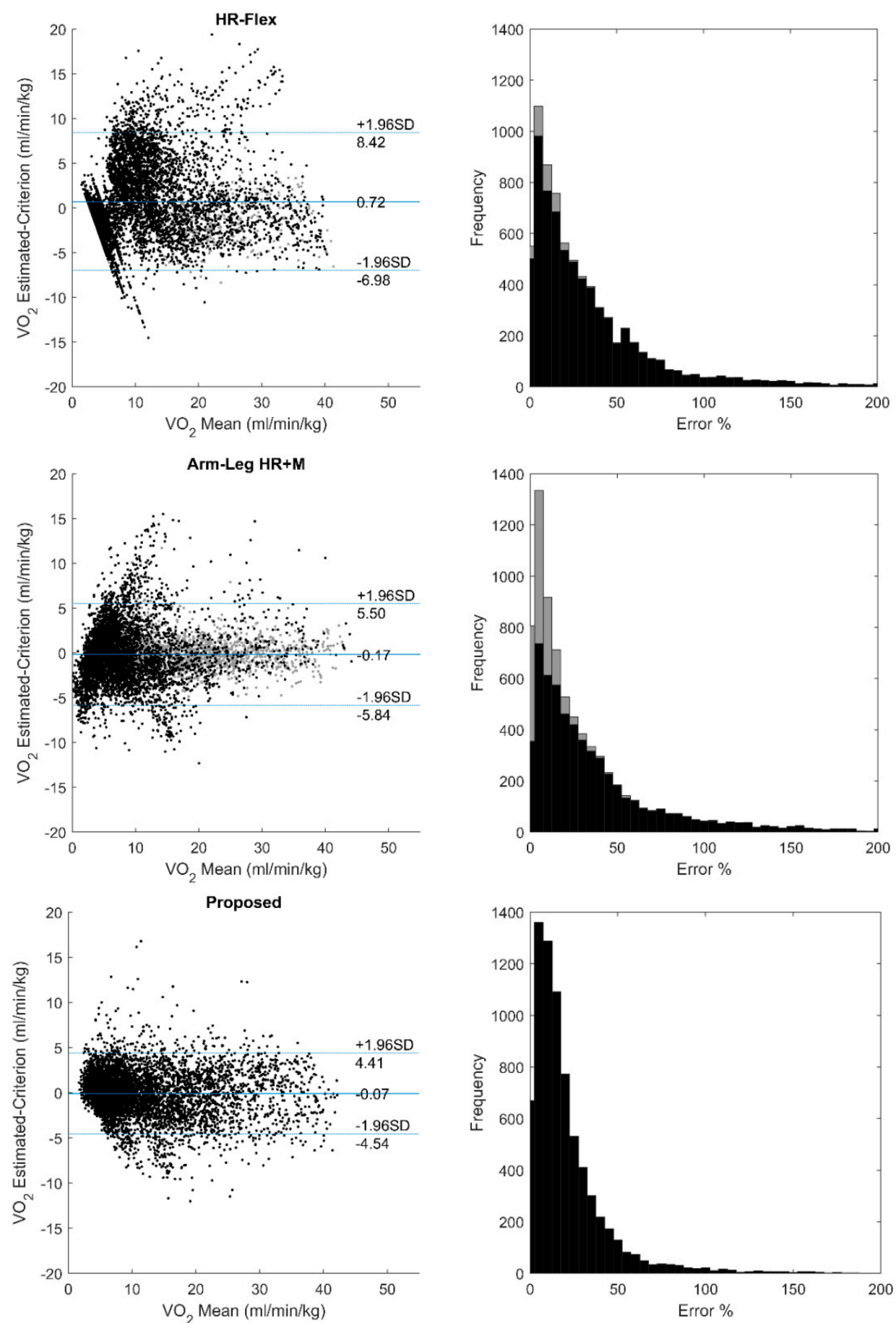

Figure 3. Bland-Altman plots and error rate histograms of flex-HR, arm-leg HR+M, and proposed methods against the criterion measurement. Data used in individual calibration are plotted in grey.

\section{Discussion and Conclusions}

In this study, we have demonstrated a method for free-living energy expenditure estimation that combines the HR, respiration, and motion information using nonlinear data driven modeling. In the experiment, the method showed improved accuracy over two established methods, based on HR and HR combined with ACC.

The method has also improved the usability by avoiding a complex laboratory calibration. The Chester step test used for $\mathrm{VO}_{2}$ max estimation only requires a step with designed height, and takes only 6 to $10 \mathrm{~min}$, which can be easily applied in the field. For certain ergonomic applications that 
use per cent maximum aerobic capacity $\left(\% \mathrm{VO}_{2} \max \right)$ as a measure of physical workload, the output of the network can be used directly without the need of multiplying individual $\mathrm{VO}_{2}$ max value; hence, no calibration procedure is required. The wearable system used in the study is light-weight and easy to wear, which opens up the possibility for long-term, unobtrusive monitoring in different contexts. However, different contexts will come with different needs regarding number of accelerometers and their placement. The most versatile system would have many accelerometers at different sites on the body, but many sensors will increase the overall price of the system. Obviously, there will be trade-off between versatility, complexity, and cost.

A method using neural network based model to estimate EE from HR has been reported previously in [31,32]. This method uses not only the HR, but also heart rate variability derived respiration rate, and HR 'on and off dynamics' as input features. However, very limited information has been shown about the implementation. Hence, we were not able to compare our method with it.

In previous studies $[15,18]$, which used portable indirect respiration monitoring devices to estimate EE, the measured physical quantities such as transthoracic impedance and thoracic circumference distance were converted into flow or volume through a personal calibration process using a spirometer. In this study, a rough calibration of the personalized impedance level was acquired by using simultaneously-measured HR values. How much data is needed to establish a reliable relationship and the durability of the relationship should be further studied. In the experiment, we found our $V_{E-r e l}$ measurement through IP did not have very high linearity with the $V_{E}$ measured by the indirect calorimetry. Possible causes for this discrepancy include the configuration of electrode position, posture change that alters the shape of ribcage [49], and motion artifacts. Applying optimized IP electrodes position [50] and advanced processing methods will have the potential to improve the IP measurement hence the EE estimation.

Limitations of this study include a small sample size (11 subjects), and the fact that limited activity types were performed under laboratory condition. The method has not yet been validated for complex real free-living scenarios, and the trained network could be overfitted to the activities that were performed in the experiment. The experiment has not taken into consideration many nonmetabolic-related factors that may alter $\mathrm{HR}$ or $\mathrm{V}_{\mathrm{E}}$, such as mental stress and temperature.

Since the new model showed a higher level of agreement with the reference methods compared to two existing methods, this study indicates a high potential for applying information fusion of HR, respiration, and motion data in combination with a nonlinear statistical learning method in the field of unobtrusive energy expenditure estimation. The solution may be used both in occupational and general health applications. Studies with improved respiration monitoring techniques and varied populations with larger size under free-living conditions are suggested in future development.

Author Contributions: L.Y. and K.L. conceived and designed the experiments in collaboration with the other authors; L.Y. and K.L. performed the experiments; K.L. analyzed the data; F.S. contributed with wearables; all authors participated in the discussion of results; K.L. drafted the paper; all authors revised the paper.

Funding: This work was supported by AFA Insurance under Grant Dnr 150039, EIT Health under project no. 18454 "Wellbeing, Health and Safety @ Work", and CSC Scholarship Council.

Conflicts of Interest: Kaj Lindecrantz and Fernando Seoane are co-founders and partial owners of Z-Health Technologies AB, Borås, Sweden. The other authors declare no conflict of interest.

\section{References}

1. Wu, H.C.; Wang, M.J. Relationship between Maximum Acceptable Work Time and Physical Workload. Ergonomics 2002, 45, 280-289. [CrossRef] [PubMed]

2. Colberg, S.R.; Sigal, R.J.; Yardley, J.E.; Riddell, M.C.; Dunstan, D.W.; Dempsey, P.C.; Horton, E.S.; Castorino, K.; Tate, D.F. Physical Activity/Exercise and Diabetes: A Position Statement of the American Diabetes Association. Diabetes Care 2016, 39, 2065-2079. [CrossRef] [PubMed]

3. Shephard, R.J.; Aoyagi, Y. Measurement of Human Energy Expenditure, with Particular Reference to Field Studies: An Historical Perspective. Eur. J. Appl. Physiol. 2012, 112, 2785-2815. [CrossRef] [PubMed] 
4. Albinali, F.; Intille, S.; Haskell, W.; Rosenberger, M. Using Wearable Activity Type Detection to Improve Physical Activity Energy Expenditure Estimation. In Proceedings of the 12th ACM International Conference on Ubiquitous Computing, Copenhagen, Denmark, 26-29 September 2010.

5. Altini, M.; Penders, J.; Amft, O. Energy Expenditure Estimation Using Wearable Sensors: A New Methodology for Activity-Specific Models. In Proceedings of the Conference on Wireless Health, San Diego, CA, USA, 23-25 October 2012.

6. Altini, M.; Penders, J.; Vullers, R.; Amft, O. Estimating Energy Expenditure Using Body-Worn Accelerometers: A Comparison of Methods, Sensors Number and Positioning. IEEE J. Biomed. Health Inform. 2015, 19, 219-226. [CrossRef] [PubMed]

7. Bonomi, A.G.; Plasqui, G.; Goris, A.H.; Westerterp, K.R. Improving Assessment of Daily Energy Expenditure by Identifying Types of Physical Activity with a Single Accelerometer. J. Appl. Physiol. 2009, 107, 655-661. [CrossRef] [PubMed]

8. Bouten, C.V.; Westerterp, K.R.; Verduin, M.; Janssen, J.D. Assessment of Energy Expenditure for Physical Activity Using a Triaxial Accelerometer. Med. Sci. Sports Exerc. 1994, 23, 21-27. [CrossRef]

9. Brage, S.; Brage, N.; Franks, P.W.; Ekelund, U.; Wong, M.Y.; Andersen, L.B.; Froberg, K.; Wareham, N.J. Branched Equation Modeling of Simultaneous Accelerometry and Heart Rate Monitoring Improves Estimate of Directly Measured Physical Activity Energy Expenditure. J. Appl. Physiol. 2004, 96, 343-351. [CrossRef] [PubMed]

10. Brage, S.; Westgate, K.; Franks, P.W.; Stegle, O.; Wright, A.; Ekelund, U.; Wareham, N.J. Estimation of Free-Living Energy Expenditure by Heart Rate and Movement Sensing: A Doubly-Labelled Water Study. PLoS ONE 2015, 10, e0137206. [CrossRef] [PubMed]

11. Crouter, S.E.; Churilla, J.R.; Bassett, D.R. Estimating Energy Expenditure Using Accelerometers. Eur. J. Appl. Physiol. 2006, 98, 601-612. [CrossRef] [PubMed]

12. Ellis, K.; Kerr, J.; Godbole, S.; Lanckriet, G.; Wing, D.; Marshall, S. A Random Forest Classifier for the Prediction of Energy Expenditure and Type of Physical Activity from Wrist and Hip Accelerometers. Physiol. Meas. 2014, 35, 2191. [CrossRef] [PubMed]

13. Eston, R.G.; Rowlands, A.V.; Ingledew, D.K. Validity of Heart Rate, Pedometry, and Accelerometry for Predicting the Energy Cost of Children's Activities. J. Appl. Physiol. 1998, 84, 362-371. [CrossRef] [PubMed]

14. Gastinger, S.; Donnelly, A.; Dumond, R.; Prioux, J. A Review of the Evidence for the Use of Ventilation as a Surrogate Measure of Energy Expenditure. J. Parenteral Enteral Nutr. 2014, 38, 926-938. [CrossRef] [PubMed]

15. Gastinger, S.; Nicolas, G.; Sorel, A.; Sefati, H.; Prioux, J. Energy Expenditure Estimate by Heart-Rate Monitor and a Portable Electromagnetic-Coil System. Int. J. Sport Nutr. Exerc. Metab. 2012, 22, 117-130. [CrossRef] [PubMed]

16. Hiilloskorpi, H.; Fogelholm, M.; Laukkanen, R.; Pasanen, M.; Oja, P.; Mänttäri, A.; Natri, A. Factors Affecting the Relation between Heart Rate and Energy Expenditure During Exercise. Int. J. Sports Med. 1999, 20, 438-443. [CrossRef]

17. Jang, Y.; Jung, M.W.; Kang, J.; Kim, H.C. An Wearable Energy Expenditure Analysis System Based on the 15-Channel Whole-Body Segment Acceleration Measurement. In Proceedings of the 2005 27th Annual International Conference of the Engineering in Medicine and Biology Society, Shanghai, China, 1-4 September 2005.

18. Lu, K.; Yang, L.; Abtahi, F.; Lindecrantz, K.; Rödby, K.; Seoane, F. Wearable Cardiorespiratory Monitoring System for Unobtrusive Free-Living Energy Expenditure Tracking. In Proceedings of the World Congress on Medical Physics and Biomedical Engineering 2018, Prague, Czech Republic, 3-8 June 2018.

19. Li, R.; Deurenberg, P.; Hautvast, J.G. A Critical Evaluation of Heart Rate Monitoring to Assess Energy Expenditure in Individuals. Am. J. Clin. Nutr. 1993, 58, 602-607. [CrossRef] [PubMed]

20. Lin, C.W.; Yang, Y.T.; Wang, J.S.; Yang, Y.C. A Wearable Sensor Module with a Neural-Network-Based Activity Classification Algorithm for Daily Energy Expenditure Estimation. IEEE Trans. Inform. Technol. Biomed. 2012, 16, 991-998.

21. Livingstone, M.B. Heart-Rate Monitoring: The Answer for Assessing Energy Expenditure and Physical Activity in Population Studies? Br. J. Nutr. 1997, 78, 869-871. [CrossRef] [PubMed] 
22. Livingstone, M.B.; Prentice, A.M.; Coward, W.A.; Ceesay, S.M.; Strain, J.J.; McKenna, P.G.; Nevin, G.B.; Barker, M.E.; Hickey, R. Simultaneous Measurement of Free-Living Energy Expenditure by the Doubly Labeled Water Method and Heart-Rate Monitoring. Am. J. Clin. Nutr. 1990, 52, 59-65. [CrossRef] [PubMed]

23. Lu, K.; Yang, L.; Abtahi, F.; Lindecrantz, K.; Rödby, K.; Seoane, F. Wearable Cardiorespiratory Monitoring System for Unobtrusive Free-Living Energy Expenditure Tracking; Springer: Singapore, 2019.

24. Luke, A.; Maki, K.C.; Barkey, N.; Cooper, R.; McGEE, D.A. Simultaneous Monitoring of Heart Rate and Motion to Assess Energy Expenditure. Med. Sci. Sports Exerc. 1997, 29, 144-148. [CrossRef] [PubMed]

25. Meijer, G.A.; Westerterp, K.R.; Koper, H.A. Assessment of Energy Expenditure by Recording Heart Rate and Body Acceleration. Med. Sci. Sports Exerc. 1989, 21, 343-347. [CrossRef] [PubMed]

26. Montoye, H.J.; Washburn, R.I.; Servais, S.T.; Ertl, A.N.; Webster, J.G.; Nagle, F.J. Estimation of Energy Expenditure by a Portable Accelerometer. Med. Sci. Sports Exerc. 1983, 15, 403-407. [CrossRef] [PubMed]

27. Murakami, H.; Kawakami, R.; Nakae, S.; Nakata, Y.; Ishikawa-Takata, K.; Tanaka, S.; Miyachi, M. Accuracy of Wearable Devices for Estimating Total Energy Expenditure: Comparison with Metabolic Chamber and Doubly Labeled Water Method. JAMA Internal Med. 2016, 176, 702-703. [CrossRef] [PubMed]

28. Spurr, G.B.; Prentice, A.M.; Murgatroyd, P.R.; Goldberg, G.R.; Reina, J.C.; Christman, N.T. Energy Expenditure from Minute-by-Minute Heart-Rate Recording: Comparison with Indirect Calorimetry. Am. J. Clin. Nutr. 1988, 48, 552-559. [CrossRef] [PubMed]

29. Strath, S.J.; Bassett, J.D.; Thompson, D.L.; Swartz, A.M. Validity of the Simultaneous Heart Rate-Motion Sensor Technique for Measuring Energy Expenditure. Med. Sci. Sports Exerc. 2002, 34, 888-894. [CrossRef] [PubMed]

30. Swartz, A.M.; Strath, S.J.; Bassett, D.R.; O'brien, W.L.; King, G.A.; Ainsworth, B.E. Estimation of Energy Expenditure Using Csa Accelerometers at Hip and Wrist Sites. Med. Sci. Sports Exerc. 2000, 32, S450-S456. [CrossRef] [PubMed]

31. Pulkkinen, A.; Kettunen, J.; Martinmäki, K.; Saalasti, S.; Rusko, H.K. On-and Off Dynamics and Respiration Rate Enhance the Accuracy of Heart Rate Based Vo2 Estimation. In Proceedings of the 51st Annual Meeting of the American College of Sports Medicine, Indianapolis, IN, USA, 2-5 June 2004.

32. Pulkkinen, A.; Saalasti, S.; Rusko, H.K. Energy Expenditure Can Be Accurately Estimated from Hr without Individual Laboratory Calibration. In Proceedings of the 52nd Annual Meeting of the American College of Sports Medicine, Nashville, TN, USA, 1-4 June 2005.

33. Brage, S.; Ekelund, U.; Brage, N.; Hennings, M.A.; Froberg, K.; Franks, P.W.; Wareham, N.J. Hierarchy of Individual Calibration Levels for Heart Rate and Accelerometry to Measure Physical Activity. J. Appl. Physiol. 2007, 103, 682-692. [CrossRef] [PubMed]

34. Vokac, Z.H.; Bell, H.; Bautz-Holter, E.; Rodahl, K. Oxygen Uptake/Heart Rate Relationship in Leg and Arm Exercise, Sitting and Standing. J. Appl. Physiol. 1975, 39, 54-59. [CrossRef] [PubMed]

35. Crouter, S.E.; Kuffel, E.; Haas, J.D.; Frongillo, E.A.; Bassett, D.R., Jr. A Refined 2-Regression Model for the Actigraph Accelerometer. Med. Sci. Sports Exerc. 2010, 42, 1029. [CrossRef] [PubMed]

36. Strath, S.J.; Brage, S.Ø.; Ekelund, U. Integration of Physiological and Accelerometer Data to Improve Physical Activity Assessment. Med. Sci. Sports Exerc. 2005, 37, S563-S571. [CrossRef] [PubMed]

37. Gilgen-Ammann, R.; Koller, M.; Huber, C.; Ahola, R.; Korhonen, T.; Wyss, T. Energy Expenditure Estimation from Respiration Variables. Sci. Rep. 2017, 7, 15995. [CrossRef] [PubMed]

38. Gastinger, S.; Sorel, A.; Nicolas, G.; Gratas-Delamarche, A.; Prioux, J. A Comparison between Ventilation and Heart Rate as Indicator of Oxygen Uptake During Different Intensities of Exercise. J. Sports Sci. Med. 2010, 9, 110-118. [PubMed]

39. Loriga, G.; Taccini, N.; de Rossi, D.; Paradiso, R. Textile Sensing Interfaces for Cardiopulmonary Signs Monitoring. In Proceedings of the 27th Annual International Conference of the Engineering in Medicine and Biology Society, New York, NY, USA, 31 August-3 September 2006.

40. Seoane, F.; Ferreira, J.; Alvarez, L.; Buendia, R.; Ayllón, D.; Llerena, C.; Gil-Pita, R. Sensorized Garments and Textrode-Enabled Measurement Instrumentation for Ambulatory Assessment of the Autonomic Nervous System Response in the Atrec Project. Sensors 2013, 13, 8997-9015. [CrossRef] [PubMed]

41. De Rossi, D.; Carpi, F.; Lorussi, F.; Mazzoldi, A.; Paradiso, R.; Scilingo, E.P.; Tognetti, A. Electroactive Fabrics and Wearable Biomonitoring Devices. AUTEX Res. J. 2003, 3, 180-185. 
42. Lanatà, A.; Scilingo, E.P.; Nardini, E.; Loriga, G.; Paradiso, R.; De-Rossi, D. Comparative Evaluation of Susceptibility to Motion Artifact in Different Wearable Systems for Monitoring Respiratory Rate. IEEE Trans. Inform. Technol. Biomed. 2010, 14, 378-386. [CrossRef] [PubMed]

43. Młyńczak, M.C.; Niewiadomski, W.; Żyliński, M.; Cybulski, G.P. Ambulatory Impedance Pneumography Device for Quantitative Monitoring of Volumetric Parameters in Respiratory and Cardiac Applications. In Proceedings of the Computing in Cardiology Conference (CinC), Cambridge, MA, USA, 7-10 September 2014.

44. Abtahi, F.; Yang, L.; Lindecrantz, K.; Seoane, F.; Diaz-Olivazrez, J.A.; Ke, L.; Eklund, J.; Teriö, H.; Mediavilla Martinez, C.; Tiemann, C. Big Data \& Wearable Sensors Ensuring Safety and Health@ Work. In Proceedings of the GLOBAL HEALTH 2017, The Sixth International Conference on Global Health Challenges, Barcelona, Spain, 12-16 November 2017.

45. Yang, L.; Lu, K.; Diaz-Olivares, J.A.; Seoane, F.; Lindecrantz, K.; Forsman, M.; Abtahi, F.; Eklund, J.A. Towards Smart Work Clothing for Automatic Risk Assessment of Physical Workload. IEEE Access 2018, 6, 40059-40072. [CrossRef]

46. Mohino-Herranz, I.; Gil-Pita, R.; Ferreira, J.; Rosa-Zurera, M.; Seoane, F. Assessment of Mental, Emotional and Physical Stress through Analysis of Physiological Signals Using Smartphones. Sensors 2015, 15, 25607-25627. [CrossRef] [PubMed]

47. Sykes, K.; Roberts, A. The Chester Step Test-A Simple yet Effective Tool for the Prediction of Aerobic Capacity. Physiotherapy 2004, 90, 183-188. [CrossRef]

48. Yang, L.; Lu, K.; Forsman, M.; Lindecrantz, K.; Seoane, F.; Ekblom, Ö.; Eklund, J. Development of Smart Wearable Systems for Physiological Workload Assessment Using Heart Rate and Accelerometry. Unpublished work. 2018.

49. Seppa, V.P.; Viik, J.; Hyttinen, J. Assessment of Pulmonary Flow Using Impedance Pneumography. IEEE Trans. Biomed. Eng. 2010, 57, 2277-2285. [CrossRef] [PubMed]

50. Seppä, V.P.; Hyttinen, J.; Uitto, M.; Chrapek, W.; Viik, J. Novel Electrode Configuration for Highly Linear Impedance Pneumography. Biomed. Eng. 2013, 58, 35-38. [CrossRef] [PubMed]

(C) 2018 by the authors. Licensee MDPI, Basel, Switzerland. This article is an open access article distributed under the terms and conditions of the Creative Commons Attribution (CC BY) license (http:// creativecommons.org/licenses/by/4.0/). 